\title{
ASO Visual Abstract: Contemporary Incidence of Medical Inoperability in Clinical Stage I Endometrial Cancer
}

\author{
Michelle Ertel, $\mathrm{MD}^{1,2}$, S. Allison Staley, MD, MPH ${ }^{1,2,3,4}$, Tam Nguyen, BA ${ }^{1}$, Austin Johnson, MD ${ }^{1,2}$, \\ Austin Hopkins, BA ${ }^{1}$, Nerlyne Desravines, $\mathrm{MD}^{1,2}$, Johnathan Recknagel, $\mathrm{MD}^{1,2}$, Xinyi Zhang, $\mathrm{MS}^{1,5}$, \\ Xianming Tan, $\mathrm{PhD}^{1,4,5}$, and Leslie $\mathrm{H}$. Clark, $\mathrm{MD}^{1,2,3,4}$ \\ ${ }^{1}$ University of North Carolina, Chapel Hill, NC; ${ }^{2}$ Division of Gynecologic Oncology, Department of Obstetrics and \\ Gynecology, University of North Carolina, Chapel Hill, NC; ${ }^{3}$ Division of Gynecologic Oncology, University of North \\ Carolina, Chapel Hill, NC; ${ }^{4}$ Lineberger Comprehensive Cancer Center, University of North Carolina, Chapel Hill, NC; \\ ${ }^{5}$ Department of Biostatistics, University of North Carolina, Chapel Hill, NC
}

This report provides an updated rate for the incidence of medical inoperability among women with endometrial cancer against a backdrop of improved surgical techniques for increasingly obese and medically complex patients (https://doi.org/10.1245/s10434-021-10313-6).

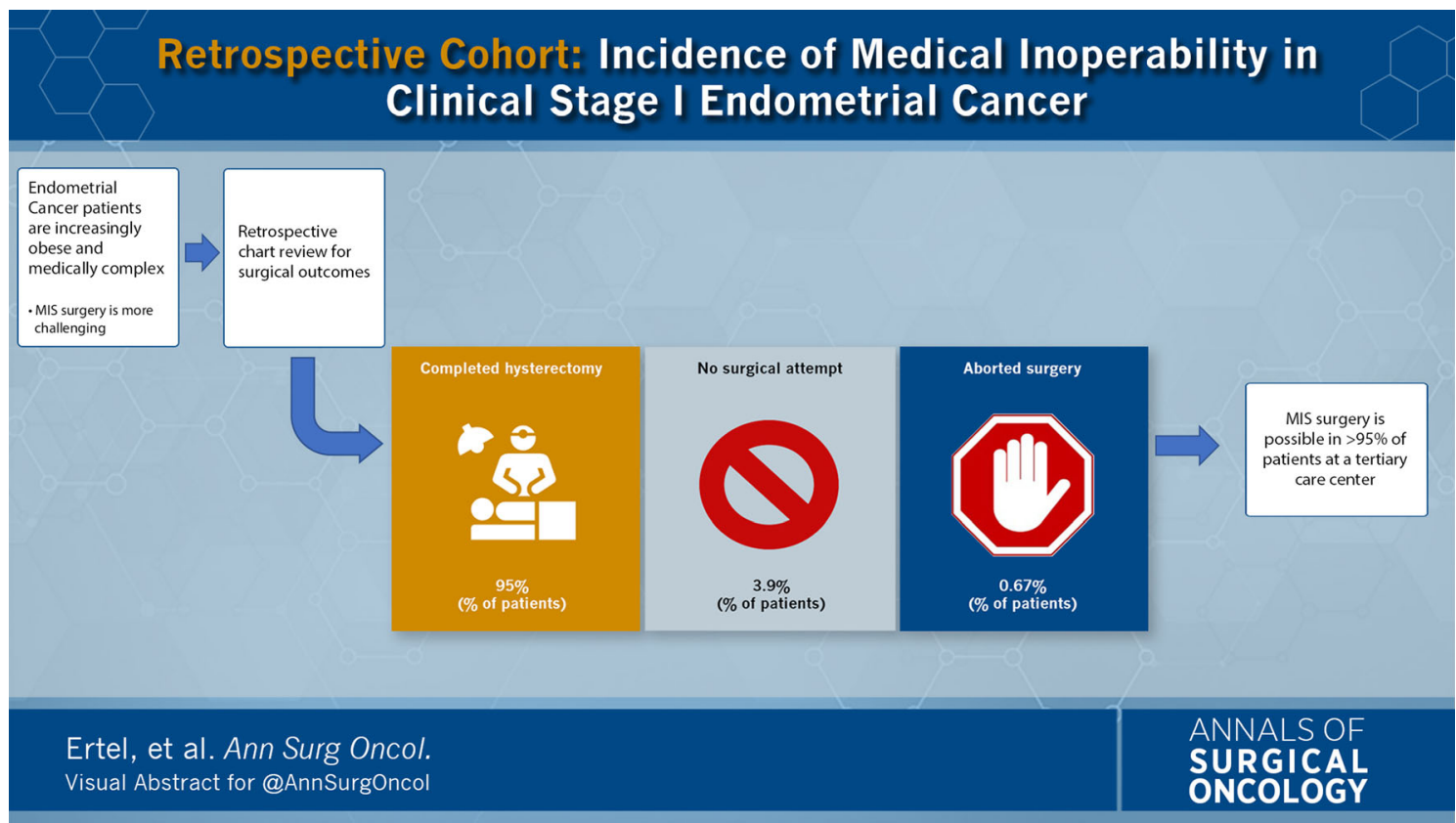

(C) Society of Surgical Oncology 2021

Published Online: 22 July 2021

L. H. Clark, MD

e-mail: Leslie_Clark@med.unc.edu
DISCLOSURE There are no conflicts of interest.

Publisher's Note Springer Nature remains neutral with regard to jurisdictional claims in published maps and institutional affiliations. 